poison known which is so sudden in its operation; and that pus, simply as such, produces no such symptoms, we have abundant proof from those cases in which it has passed without obstruction in the course of the circulation.

In a Report of a Committee of the Edinburgh Physiological Society of the 9th of January, 1853, upon some experiments undertaken at the instigation of Professor Bennett, it is stated, that fresh and healthy pus was slowly injected towards the heart into the jugular vein of a donkey. A slight obstruction was at first perceived, and the vein above the ligature could be seen to be somewhat swollen. This swelling, on being felt, was very soft, and, on pressing the vein from below upward, the mixed blood and pus was readily pushed before the finger. When all obstruction to the passage of pus from the syringe was removed, the syringe was again filled, and another ounce of pus was injected, without occasioning any further local effects. The animal was then allowed to get up, and exhibited no change in its normal condition whatever. The same ass was the subject of a second experiment, a fortnight later, having been perfectly well in the interval. Six inches of the jugular vein were now exposed, and an ounce of perfectly healthy pus was then slowly injected downwards towards the heart. Another syringe full of pus was then injected. The animal presented no unusual symptom whatever during the next four days.

To what, then, are to be attributed the sudden and fatal effects observed in Mr. Gamgee's and in Dr. Mackenzie's cases? I answer, to the coagulation of the blood in the heart. It is to this that are to be ascribed the sudden and fatal results in the cases which these gentlemen have recorded; and to the absence of any such result, that the corresponding absence of symptoms must be assigned in the last mentioned experiments.

Thus, I conceive that, while it is fully demonstrated that, in certain cases, pus may pass into the circulation without producing any very manifest inconvenience, that, in others, it will produce coagulation of the blood in the lining vessels, and a train of consequent symptoms which will vary according to the locality in which such stagnation has taken place. What the circumstances are which, in one case, will determine this effect, and in another not, will form the sulject of a separate inquiry. For the present, I must content myself with having shown, as I believe, from independent evidence derived from experiments undertaken to illustrate other and different views, that the doctrine which I first published in 1849 is not devoid of foundation; and that the propositions which $I$ then endeavoured to establish,-namely, that pus and some other morbid fluids, when mixed with the blood, have a tendency to produce its coagulation, and that this tendency is often more quickly manifested in the body than out of it,-have been fully demonstrated.

15 Dover Street, Piccadilly, Dec. 13th, 1883.

\section{DESCRIPTION OF A NEW BEDSTEAD FOR DIRTY INSANE PERSONS.}

\author{
By JAMISS G. DAVEY, M.D.
}

[Read before the Anniversary Meeting of the Provincial Medical and Suryical Associution, dugust 11 th, 1853.]

Amosg the insane there are, and always must be, even in the best recrulated of asylums, and with the greatest care and attention, a considerable number whose mental existence is relucel to so low an ebb, that the calls of nature are either not heeded, or are kept in abeyance by an inordinate cerebral excitcment, or by some absorbing and abnormal impulse, which involves the volition of the party affecter in disorder and irregularity (mania). These constitute what in asylum parlance are called dirty patients; and, for their management. and accommodation, various plans have, at different times, been suggested. In the olden time, this class of patients was very summarily dealt with. $\Lambda$ little loose straw, and that not over clean, was thrown into the corner of a damp and dirty cell; and the poor lunatic was fortunate indeed to have this exchanged when it was needed. At a less distant period, the straw was put into a coarse kind of sacking. After the lapse of time, however, both the loose straw and the coarse straw mattresses were abandoned, and their place was supplied by the common stretcher. This consists only of a stout piece of canvas extended over a framework of wood, of the length and breadth of the crib, and into which it is received. This arrangement is not unattended with much danger, inasmuch as violently disposed persons commonly remove the stretcher, and use it as a weapon of offence ; or not infrequently break it into pieces, and do more or less mischief in and about the dormitory. To meet these grave objections, various ingenious plans are derised to fasten or lock the stretcher to the crib or bedstead.

Two objections are made, and very properly, to these stretchers: one is, that the canvas, if sufficiently strong, is not porous enough to allow the urine to escape ; it is, therefore, retained more or less about the person of the patient, and risk is thereby incurred of sores: the other is the time and labour demanded, not only to wash and dry the stretcher for further use, but to carry it to and from the laundry and the wards.

The first objection has been met by piercing holes in the canvas, similar to those which tailors are in the habit of making on the back parts of waistcoats, to enable us, in physiological phrase, to adapt the containing to the contained parts. The due escape of the animal fluids, however, leaves yet the second objection untouched; and to remore this very serious business, in a lunatic asylum containing any number of patients, is the especial purpose of the cane bedstead, to which I would here call attention.

By referring to the drawing, it is seen that the whole depth of the crib is divided into two parts, an under and an upper, by the cane flap or partition which intersects it in its whole length and breadth. On the one side of the interior of the crib, the cane flap or shifting bottom is held on hinges; and, on the other side, it fastens with a kind of spring lock, which is opened from the outer side or exterior by a key of a peculiar construction. The specific value of the above arrangeunent consists in the employment of cane in the stead of canvas. This material, from the great abundance of silica which it contains, mixed with regetable matter, offers a non-absorbing surface to the urine; and all the washing, therefore, which it requires may be performed hy a damp piece of flannel, which may be used daily by the ward-attendants themselves in the dormitory, as the crib stands, with scarcely any trouble. (Figs. 1 and 3.)
Fig. 1.

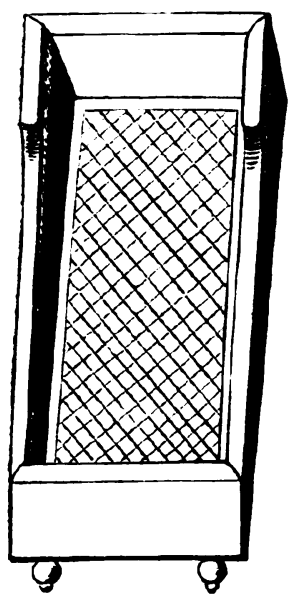

Fig 2.

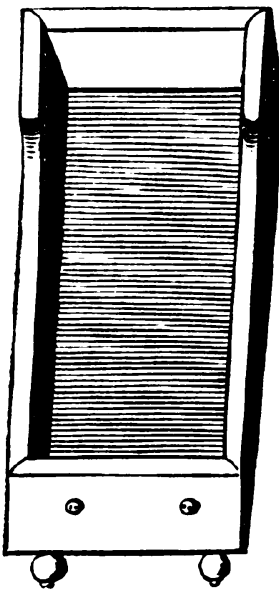

Fig. 1 represents the bedstead with the cane flap put down, and in position for use. On the rane flap the bedding is placed. N.B. The finer the canework the better.

Fig. 2 represents the bedstead with the canras expanded by the iron rods placed on either side: and which, passing from the head to the foot-board, preserre the same in sitw. 
The lead which lines the interior and bottom of the crib must of course be kept perfectly clean, as is done under any other circumstances. The addition of the ordinary drawer, containing a common chamber utensil, either of earthen ware or gutta percha, would together constitute an admirable piece of furniture for the lunatic asylum.

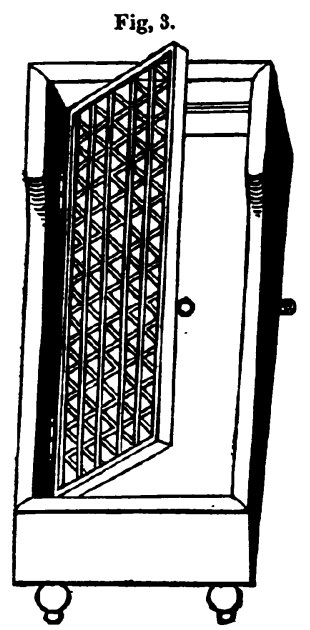

Fig. 4.

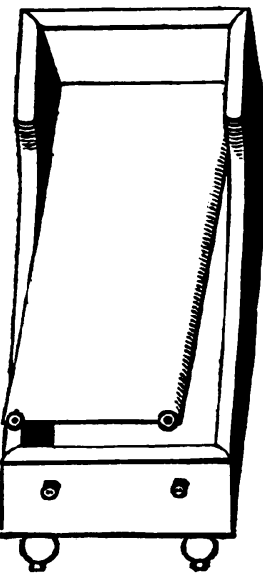

Fig. 3. In this drawing the cane flap is raised on its hinges; on one side is shown the bolt withdrawn, by meuns of which the Hap is secured by an appropriate key, in its right place, when in use.

Fig. 4. In this drawing the canvas, with the rods, by means of which it is extencled, is raised, in urder to show its relation to the contiguous paits. Like the caue fip, the

There is another form of bedstead, which is doubtles greatly to be preferred to the canvas stretcher above referred to ; but I think myself it is inferior to the cane bedstead here submitted for inspection. Its peculiarity consists in a contrivance which allows of the ready separation of the canvas from the framework to which it is attached in the crib; the frame itself being a fixture, or a part of the crib. The canvas, in this instance, may be described as a common kind of sack, equally open at either end. This is slipped on or off certain iron rods, which secure it, as required; and these are attached by a joint on each side to the upper and interior part or head of the crib, and are continued to the lower and interior or foot of the same. These rods are perfectly close to its sides, where, at points corresponding to the said joints superiorly, they fall into grooves on the interior of the foot-board, which proceed from the centre to the sides of the crib. The canvas or sacking, being slid on the iron rods, is readily extended across the bedstead; and on it of course the patient lies. The whole is secured by two common screws, which are reached from the outer side and foot of the bedstead. A piece of canvas, six feet by two, is more conveniently carried to and from the laundry and the wards, and much more casily washed and dried, than the frame or stretcher could possibly be. (Figs. 2 and 4.)

I am bound to acknowledge the assistance given to me, in matters of detail, in the contrivance of these two cribs or bedsteads, by Mr. Holman, the engineer of the County Asylum at Colney Hatch, whose mechanical ingenuity is of no ordinary kind.

Care should be taken not to fix either the cane flap or the iron rods too near the top of the crib, else the patient will lose the security the crib affords him. Those among the insane who are hopelessly of dirty habits, are, as a rule, more or less helpless and imbecile or demented. I may add, that dirty patients, in asylums for the insane, are not infrequently put to sleep on mattresses covered with oiled silk or India-rubber sheeting; and, in the centre of each mattrass, and of its coverlid, there is commonly a hole through which the animal fluids may pass away. But not only do these not answer the purpose intended, but the urine is retained in parts about the surface, and so keeps the posteriors of the patient saturated with moisture: moreover, their expense is very great.

In conclusion, I may remark, that both the kinds of erib are in use at the Colney Hatch Asylum, and, I am told, at the Asylum at Hanwell. I am assured, too, that, at the former institution, they continue to be highly approved.

Northwoods, Bristol, Aug. 8th, 1859.

\section{BIBLIOGRAPHICAL NOTICES.}

A Text-Boor of Physiologr. By Dr. G. Valertir, Professor of Physiology in the University of Berne. Translated and Edited from the Third German Edition,

by Wilhiax Briston, M.D. Part II. London : 1853. WE have already noticed in favourable terms the First Part of the translation of Valentin's Physiology by Dr. Brintor. The whole work is now before us, and we can conscientiously speak in its praise. It is described by $\mathrm{Dr}$. Brinton as an abridgement, by Dr. Valentin, of the last edition of his larger systematic treatise, the "Lehrbuch der Physiologie."

The book is divided into nineteen chapters, which treat successively of Organization and Life, of Organic and Animal Functions, of the Physical and Chemical Properties of the Body, of Digestion, Absorption, Circulation, Respiration, Evaporation, and Secretion ; of the Vascular Glands, by which term the author designates the spleen, the suprarenal capsules, the thyroid and the thymus glands; of Nutrition, Animal Heat, Locomotion, and the Voice ; of the Functions of the Senses, of Innervation ; and lastly, of $\mathrm{Ge}_{\theta-}$ neration and Development.

To offer any detailed opinion upon the merits of Professor Valentin as a physiologist may be deemed superfluous, when we consider the high reputation which he already enjovs upon the Continent. We shall therefore only remark that he possesses those qualities of mind, natural and acquired, which render him a trustworthy authority in matters of science. He is fully acquainted with the literature of physiology and with the collateral sciences on which its principles are founded; and he has moreover enriched his pages with many ingenious experiments devised and executed by himself. He is a calm and dispassionate critic of the many disputed points in physiology; and his own views are always based upon extensive knowledge and correct reasoning.

We do not by any means affirm that, as a Treatise on Physiology, the present work is decidedly superior to other books upon the same subject, especially the works of Müller and of Carpenter; but as this department of science is one which is continually changing its features, in consequence of recent discoveries in histology and chemistry, of the different aspects in which the same truths may be presented to different minds, and of the institution of new experiments, a work on this subject coming from a philosophic writer and experimentalist is always acceptable ; and Valentin's present contribution to physiology is one of the highest order. Modern physiology is like a kaleidoscope, in which the most dissimilar objects appear to be heterogeneously jumbled together before the ordinary observer; but it is the province of intellect to collect and arrange the scattered elements, to reduce them to system, and to unite them into a coherent and harmonious scheme. This has been done in Valentin's Text-Book, which is therefore to be recommended as a safe and useful guide to the student and the practitioner.

To Dr. Brinton a considerable meed of praise is likewise due ; the translation is carefully and neatly performed, and the notes appended to the text, although few, are welltimed and judicious.

There are no fewer than five hundred illustrations interspersed throughout the volume, on wood, copper, and stone, and some of these are of the most elaborate character, and are executed with great accuracy. 